\title{
Effect of Aloe vera juice on the hepatotoxicity induced by isoniazid drug
}

\section{G. V. Zodape}

Department of Zoology, S. S. \& L.S. Patkar College of Arts \& Science and V.P. Varde College of Commerce and Economics S.V. Road, Goregaon (West), Mumbai- 400062 (Maharashtra), INDIA

E-mail: gautamvz5@yahoo.com

\begin{abstract}
Aloe vera leaves were gently pressed and the juice obtained was collected in a sterile container. The yield was calculated based on weight of the extract compared to the weight of the leaves. Twenty (20) Wistar strain rats (average weight 120-150 g) were divided into four (4) groups containing five (5) rats in each group. Each group was fed on a different diet like the control rats were fed on commercial rat pellet; experimental rats fed orally with Aloe vera juice $1.0 \mathrm{ml} / \mathrm{kg}$ body weight and isoniazid drug (LD) $50 \mathrm{ml} / \mathrm{kg}$ body weight. Blood samples from each group were taken after $30^{\text {th }}$ day through cardiac puncture for estimation of liver function test. The extent of liver damage was assessed by quantitative estimation of serum alanine aminotransferase (serum ALT), serum aspartate aminotransferase (serum AST), serum alkaline phosphatase (serum ALP), serum acid phosphatase (serum ACP), total serum protein (albumin and globulin) and serum bilirubin. Our investigations showed that the level of bilirubin was found to be higher in aloe vera juice and isoniazid drug administered groups. The level of serum ALT was found to be highest in rat fed with isoniazid drug, whereas the level of serum AST was found lowest in rats administered with isoniazid drug. The levels of serum ALP and serum ACP were found higher in concentration in rats administered with isoniazid drug. While the level of total proteins (albumin and globulin) was found to be low in group administered with isoniazid drug. Histopathological assessment of liver revealed that the animal exposed to isoniazid drug alone showed multifocal mild degree periportal mononuclear cell infiltration. Histological lesions ranged from hepatocellar disintegration and vacuolation in the peri-central vein area to marked proliferation of the rough endoplasmic reticulum. The remaining groups, however showed normal lobular pattern of liver.
\end{abstract}

Keywords: Aloe vera, Hepatotoxicity, Isoniazid drug, Liver

\section{INTRODUCTION}

Liver is one of the largest and vital organs of human body and is vulnerable for tissue insult continuously. Liver regulates various important metabolic functions, the distortion of which causes hepatic damage (Wolf, 1999). Liver disease is still a worldwide health problem. Drug-induced hepatotoxicity is one of the major concerns which limit the therapy and drug use. About $2 \%$ of all causes of jaundice in hospitalized patients are drug induced. Approximately quarter of cases of fulminant hepatic failure are thought to be drug related. More than 900 drugs have been implicated in causing liver injury (Friedman et al., 2003) and it is the most common reason for a drug to be withdrawn from the market.

Unfortunately, conventional or synthetic drugs used in the treatment of liver diseases are inadequate and sometimes can have serious side effects. This is one of the reasons for many people in the world including those in developed countries changing to complementary and alternative medicine. Many traditional remedies employ herbal drugs for the treatment of liver ailments (Dhuley and Naik, 1997. Venkateswaran et al., 1997; Latha et al., 1999; Mitra et al., 2000).
Tuberculosis remains a global epidemic, with one third of the population infected and 9 million active cases. Mono-and multi drug resistance in 6 World Health Organization (WHO) regions have been assessed in $40 \%$ of the global cases diagnosed by positive result of sputum testing. The 2004 report of the WHO Global Project on Anti-Tuberculosis Drug Resistance Surveillance confirms earlier finding that drug resistant tuberculosis is ubiquitous and that multi drug-resistant tuberculosis has increased alarmingly .

Isoniazid drug is used for the treatment of tuberculosis. Isoniazid intake induces generalized convulsions, coma and metabolic acidosis. Liver, peripheral nervous and hematologic system are the main targets of Isoniazid chronic toxicity. Overdose of Isoniazid has been reported to produce nausea, vomiting, dizziness, slurred speech, blurred vision and visual hallucinations. Symptoms of overdose usually occur within 30 minutes to 3 hours following ingestion of the drug (Guranani et al., 1992). Death may occur from acute respiratory failure or hypertension.

Aloe vera is being used by many countries for its curative and therapeutic properties. Over 75 active ingredients from its inner gel have been identified. Many of the 
medicinal effects of Aloe vera leaf extracts have been attributed to the polysaccharides found in the parenchymatous tissue of inner leaf (Ni and Tizard, 2004); Ni et al., 2004), but it is believed that these biological activities should be assigned to a synergistic action of the compounds contained therein rather than a single chemical substance (Dagne et al., 2000).

The biological activities include promotion of wound healing, antifungal activity, hypoglycemic or antidiabetic effects, anti inflammatory, anticancer, immunomodulatory and gastro - protective properties. Other important pharmaceutical properties that have been recently discovered for both the A vera gel and whole leaf extracts includes the ability to improve bioavailability of coadministered vitamins in human subjects (Vinson et al., 2005). Furthermore, Chandan, et al. (2007) reported that, an aqueous extract of dried aerial parts of $A$. vera significantly reduced hepatic damage induced by carbon tetrachloride in mice and reversed certain biochemical parameters. An increase in bile flow and bile solids as a result of treatment with the extract suggests stimulation of the secretary activity of the liver cells. The hepatoprotective action is also attributed to preserving the metabolizing enzymes of the liver through an antioxidant activity.

\section{MATERIALS AND METHODS}

Fresh Aloe vera leaves were brought from the botanical garden of Patkar College, Goregaon (West), Mumbai, India.

Preparation and extraction: A. vera leaves were rinsed in ordinary potable water. The juice obtained from the leaves by gently pressing them was collected in a sterile container. The yield was calculated based on the weight of extract compared to the weight of leaves.

Experimental design: Twenty (20) rats Wister strain (average weight 120-150 g) were used for the experiment. They were purchased and procured from the Hafkin's Institute Parel Mumbai. The animals were maintained and housed in S.P Mandali's Animal Testing Center Ruia College, Matunga (East), Mumbai-400016, India (315/ CPCSEA). The rats were fed on commercial rat pellet. The rats were acclimatized in laboratory conditions for ten (10) days prior to the experiment. The rats were divided into four (4) groups containing five (5) rats in each group and they were fed on the following diet: Group A: Control i.e. rats fed with rat pellets and ordinary water; Group B: Rats fed orally with $A$. vera juice $1.0 \mathrm{ml} / \mathrm{kg}$ body weight for 30 days; Group C: Rats fed orally with A. vera juice1.0 $\mathrm{ml} / \mathrm{kg}$ body weight and isoniazid drug (LD) $50 \mathrm{ml} / \mathrm{kg}$ body weight for 30 days; Group D: Rats fed orally with isoniazid drug (LD) $50 \mathrm{ml} / \mathrm{kg}$ body weight for 30 days

The animals were sacrificed after the last administrations. A nalysis of the samples: 1) Blood samples of the each group were taken after $30^{\text {th }}$ day from cardiac puncture for estimation of liver functional test. Assessment of liver damage was done by biochemical investigations of serum alanine aminotransferase (serum ALT), serum aspartate aminotransferase (serum AST), serum protein, serum biliriubin, serum alkaline phosphatase (serum ALP), and serum acid phosphatase (serum ACP). 2) Histopathological assessment of liver was done using a standard method for the structural changes.

\section{RESULTS AND DISCUSSION}

The biochemical investigation of serum showed that the level of bilirubin was found to be higher in $A$. vera juice and isoniazid drug administered groups individually. The level of serum ALT was found to be highest in rat fed with isoniazid drug. The level of serum AST and total proteins (albumin and globulin) were found to be the lowest in rats administered with isoniazid drug whereas the levels of serum ALP and serum ACP were found higher.

Histopathological assessments of liver done using a standard method for the structural changes are shown in Figs. A-D.

The animals administered with isoniazid drug alone showed mildly multifocal mild degree periportal mononuclear cell infiltration. Histological lesions ranged from hepatocellar disintegration and vacuolation in the peri-central vein area to marked proliferation of the rough endoplasmic reticulum. Whereas the remaining groups showed normal lobular pattern of liver.

Yamamoto (1973) showed that a component of A. ferox suppresses ulcer growth and L-histidine decarboxylase in rats. The studies have been carried out by the protective effect of chitosan supplementation against the hepatotoxicity induced by antitubercular drugs with respect to the changes in the levels of protein, albuminglobulin ratio, urea and bilirubin in the serum and diagnostic marker enzymes (alanine amino transferase, aspartate amino transferase, acid phosphatase and alkaline phosphatase), protein, glycoprotein conjugates (hexose, hexosamine and sialic acid), lipid peroxidation and reduced glutathione in the liver tissue of normal and experimental groups of rats. The hepatoprotective potential of cimetidine in hepatotoxicity induced by isoniazid- rifampicin combination in albino rabbits has also been evaluated by many researchers and compared with the hepatoprotective and immunomodulatory effects of Curcuma longa (CL), 0 cimum sanctum (OS), Tinospora cordifolia (TC) and Zizyphus mauritiana $(\mathrm{ZM})$ on liver injury and immunosuppression induced by Isoniazid (INH), Rifampicin (RIF) and Pyrazinamide (PZA). Isoniazid, first-line drug in the treatment of tuberculosis, causes mild changes in serum transaminase levels resulting in hepatotoxicity. It is preferred to 


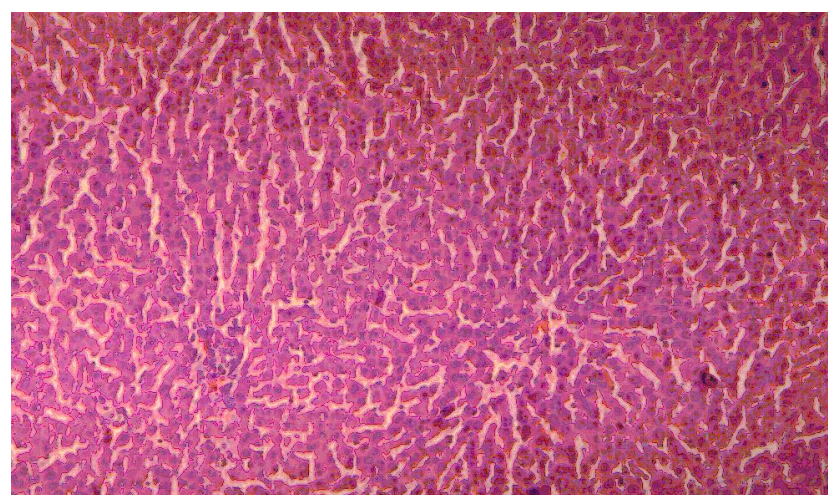

Fig. A (Group A) C1. Rats fed with rat pellets (T.S. of liver showing normal pattern).

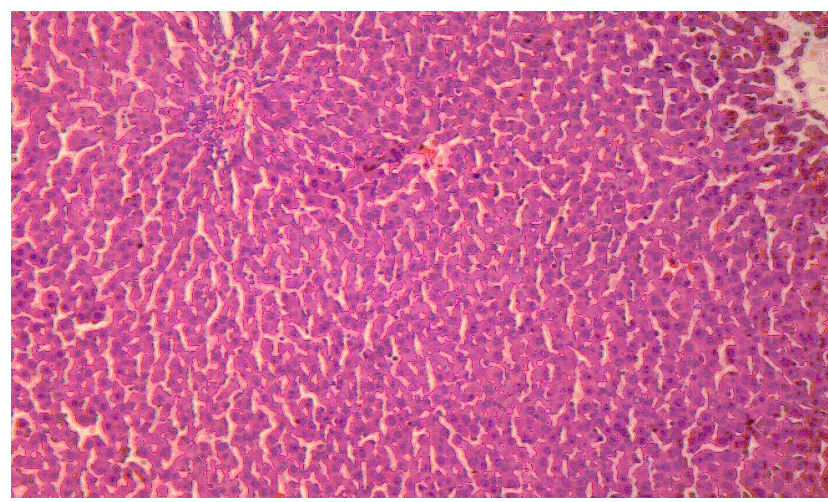

Fig. C (group C) AM 1. Aloe ver a juice + isoniazid drug (T.S. of liver showing normal pattern).

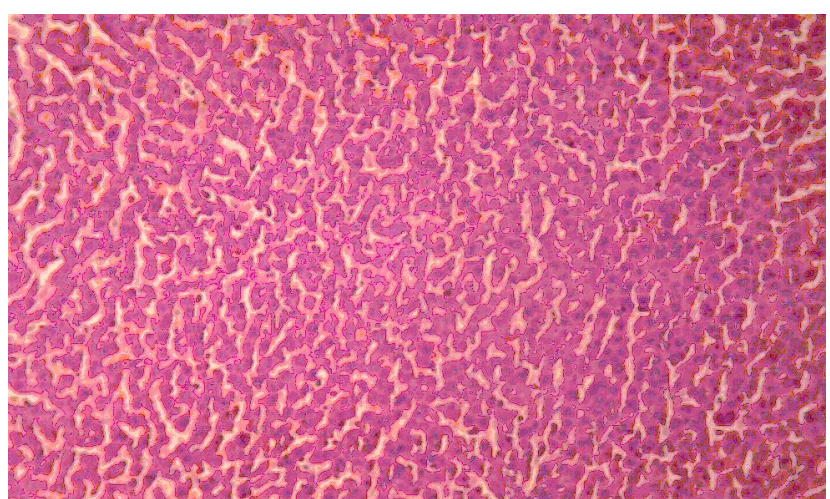

Fig. B (G roup B) A 1. Aloe vera juice (T.S. of liver showing normal pattern).

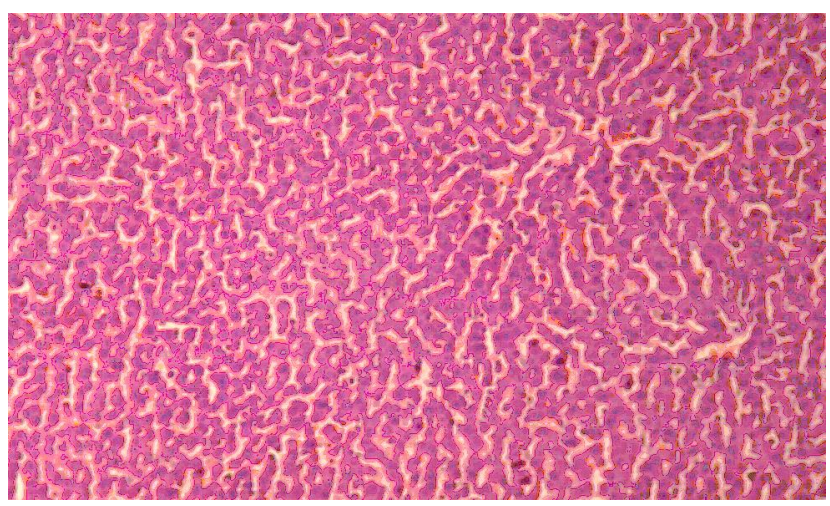

Fig. D (Group D) M 1. Rats fed orally with isoniazid drug (T.S. of liver showing mildly multifocal mild degree periportal. mononuclear cell infiltration).

Table 1. Biochemical investigations of bilirubin, serum alanine aminotransferase (serum ALT), serum aspartate aminotransferase (serum AST), serum alkaline phosphatase (serum ALP), and serum acid phosphatase (serum ACP) and serum protein.

\begin{tabular}{|c|c|c|c|c|c|c|c|c|}
\hline \multirow[t]{2}{*}{$\begin{array}{l}\text { Sample } \\
\text { Code }\end{array}$} & \multirow[t]{2}{*}{$\begin{array}{c}\text { Serum } \\
\text { Bilirubin } \\
\text { mg/dl } \\
n=5\end{array}$} & \multirow[t]{2}{*}{$\begin{array}{c}\text { Serum ALT } \\
\qquad \mathrm{IU} / \mathrm{L} \\
n=5\end{array}$} & \multirow[t]{2}{*}{$\begin{array}{c}\text { Serum AST } \\
\text { IU/L } \\
n=5\end{array}$} & \multirow[t]{2}{*}{$\begin{array}{c}\text { Serum } A L P \\
I U / L \\
n=5\end{array}$} & \multirow[t]{2}{*}{$\begin{array}{c}\text { Serum ACP } \\
\text { IU/L } \\
n=5\end{array}$} & \multicolumn{3}{|c|}{$\begin{array}{c}\text { Serum Protein } \\
\qquad / \mathrm{dl} \\
\mathrm{n}=5\end{array}$} \\
\hline & & & & & & Total & Albumin & Globulin \\
\hline C-1 & 0.3 & 112 & 34 & 93 & 15.1 & 5.2 & 3.3 & 1.9 \\
\hline A-1 & 0.4 & 113 & 35 & 87 & 19.8 & 5.4 & 3.3 & 2.1 \\
\hline AM-1 & 0.3 & 121 & 28 & 91 & 16.9 & 6.1 & 3.8 & 2.3 \\
\hline M-1 & 0.4 & 123 & 17 & 281 & 21.4 & 6.0 & 3.9 & 2.1 \\
\hline
\end{tabular}

Sample code: C1: Group A: Control i.e. rats fed with rat pellets and ordinary water, A1: Group B: Rats fed orally with A. vera juice, AM1: Group C: Rats fed orally with A. vera juice and isoniazid drug, M1: Group D: Rats fed orally with isoniazid drug

measure these levels during isoniazid treatment so that the extent of toxicity can be estimated (Mitchell et al., 1976). Hepatotoxin is mainly responsible for increased bile secretion in the serum (Rao et al., 1973). Experimental studies on animals suggest that administration of antitubercular drugs results in the rise of ALT, AST and ALP in serum, affecting hepatocellular membrane integrity and its organelles (Parthasarathy et al., 1986; Shakun and Tabachuk, 1992). Increased activity of hepatocytes leads to hyperbillirubinaemia which helps to determine integrity of liver (Singh et al., 1998).

It has been reported that sub acute or chronic treatment with isoniazid induced hepatotoxicity in man (Mitchell et al., 1974), rat (Snodgrass et al., 1974), and guinea pigs (Karthikeyan, 2004) resulting in the rise of serum transaminases and phosphatase activities.

Isoniazid-induced hepatitis is associated with ballooning degeneration, focal hepatocyte necrosis with minimal cholestasis (Mitchell et al., 1976). Another study reported diffused microvascular fatty infilteration with mild portal triadistis (Sodhi et al., 1997). Similar changes were seen in our study, confirming the validity of our animal model. We decided to perform bilirubin, ALT, AST, Alkaline phosphtase, Acid phosphatase, Total proteins and liver biopsy in order to verify the disturbed functions and actual necrotic and inflammatory changes in the liver, 
and thus histological parameters were added to support the biochemical findings. Our study obtained the similar results except the low level of AST.

\section{Conclusion}

Aloe vera has been reported to have a hepatoprotective effect in animals. In the current study, it was found that A.vera at the higher dose levels prevented an increased in ALT, AST, ALP, ACP, Bilirubin, total proteins (albumin and globulin) levels as well as the histological changes associated with A. vera - isoniazid combination. Our studies revealed the hepatoprotective nature of $A$. vera juice, and suggested that the hepatoprotective effect of A. vera juice supplementation with isoniazid drug shall increase the secretion of bile and detoxify the toxins by maintaining the liver functions. This was further confirmed by biochemical investigations and histopathological study. The study further suggests that $A$. vera juice supplementation with isoniazid drug can be used in the pharmaceutical industry for the manufacture of multi- drugs therapy.

\section{ACK NOW LEDGEMENTS}

Author is thankful to University of Mumbai for sanctioning the grant for pursuing the project. Author is also thankful to the Hafkin's Institute Parel Mumbai for providing the rats and S.P. Mandali's, Animal Testing Center, Ruia College, Matunga (East), Mumbai India for providing facilities for experimental work and also thankful to Unique Bio Diagnostics Enterprises (UBE)Veterinary Pathology Laboratory, B-20, Bhuvaneshwar, Dr. V. K. Valimbe Road, Near Gururani Nagkanya Chowk, Parel Village, Mumbai for biochemical investigation and histopathological assessment of liver.

\section{REFERENCES}

Chandan,B.K., Saxena, A. K., Shukla, S., Sharma, N., Gupta, D.K., Suri, K.A., Suri, J., Buadauria, M. and Singh, B. (2007). Hepatoprotective potential of Aloe Barbadensis Mill. Against carbon tetrachloride induced hepatotoxicity. J . Ethnopharmacol., 111: 560-566

Dagne, E., Bisrat, D., Viljoen, A. and Vanwyk, B. E. (2000). Chemistry of aloe species. Curr. Org. Chem., 1055-1078

Dhuley G. P. and Naik, S. R. (1997). Protective effect of Rhinax, a herbal formulation against CCl4 induced liver injury and survival in rats. J. Ethnopharmacol., 56: 159-164

Friedman, Scott, Grendell, E., James, H., McQuaid and Kenneth, R. (2003). Current diagnosis and treatment in gastroenterology. New York .Lang Medical books / McGrawHill. pp. 664-679.

Karthikeyan, S. (2004). Hepatotoxicity of isoniazid: A study on the activity of marker enzymes of liver toxicity in serum and liver tissue of rabbits, Indian J.Pharmacol ., 36 (4): 247249.
Latha, U., Rajesh, M.G. and Latha, M.S. (1999). Hepatoprotective effect of an ayurvedic medicine. Indian drugs, 36: 470- 473

Mitchell, J.R., Long, M.W., Thoregeirsson, U.P. and Jollow, D.J. (1974). Acetylation rates and monthly liver function tests during one year of isoniazid preventive therapy. Chest. 68: 181-190.

Mitchell, J.R., Zimmerman, H.J.,Ishak, K.G.,Thorgeirsson, U.P.,Timbrell, J.A. and Snodgrass, W.R. (1976). Isoniazid liver injury: Clinical spectrum, Pathology and probable pathogenesis. Ann. Intern. M ed., 84:181-92.

Mitra, S.K. and Seshadri, S.J. (2000). Effect of HD-03-a herbal formulation in galactosamine-induced hepatopathy in rats. Indian J. Physiol. Pharmacy, 44:82-86.

Ni, Y. and Tizard, I.R. (2004). Analytical methodology: The gel analysis of aloe.pulp and its derivatives. In aloes. The genus Aloe; Reynolds, T., ED.; CRC Press: Bock Raton, pp 111-126

Ni, Y., Turner,D., Yates, K. and Tizard, I. (2004). Isolation and characterization of structural components of Aloe vera L. leaf pulp. Int. Immunopharmacol, 4: 1745-1755

Parthasarathy, R., Sarma, G. R., Janardhanam, B., Ramachandran, P., Santha, T. and Sivasubramanian, S. (1986). Hepatic toxicity in South Indian patients during treatment of tuberculosis with short-course regimens containing isoniazid, rifampicin and pyrazinamide. Tubercle, $67: 99$ 108.

Rao, R.R. (1973). Mechanism of drug induced hepatotoxicity. I.J. Pharmacol., 5: 313-318.

Shakun, N.P. and Tabachuk, O.P. (1992). The comparative action of isoniazide,rifampicin and ethambutol on liver function. EKSP.K lin. F armakol., $55: 45$.

Singh, .B, Saxena, A.K., Chandan, B.K., Anand, K.K., Suri, O.P., Suri, K.A. and Satti, N.K. (1998). Hepatoprotective activity of verbenalin on experimental liver damage in rodents. Fitoterapia., 69: 135-140.

Snodgrass, W., Potter, W. Z., Timbrell, J. A., Jollow, D. J. and Mitchell, J.R. (1974). Possible mechanism of isoniazid related hepatic injury. Clin. Res., 22: 323

Sodhi, C.P., Rana, S.,Mehta, S., Vaiphe, K., Altari, S. and Mehta S. (1997). Study of oxidative stree in rifampicin-Induced hepatic injury in young rats. Drug Chem. Toxicol., 20: 255-69.

Venkateswaran, S., Pari, L., Viswanathan, P. and Menon, V.P. (1997). Protective effect a herbal formulation against erythromycin estolate -induced hepatotoxicity in rats. J. Ethnopharmacol., 57:161-167.

Vinson, J.A., Al Kharrat, H. and Andreoli, L.(2005). Effect of Aloe vera preparations on the human bioavailability of vitamins $\mathrm{C}$ and E. Phytomedicine, 12:760-765.

Wolf, P.L. (1999). Biochemical diagniosis of liver diseases. Indian J. Cli. Biochem., 14:59-90.

Yamamoto, I. (1973). Aloe ulcin, a new principle of Cape aloe and gastrointestinal function, especially experimental ulcer in rats. J. of the M edical Society of Toho U niver sity. 17:243347. 